\title{
Balıkesir Üniversitesi Tıp Fakültesi Araştırma ve Uygulama Hastanesinde Sağlık Çalışanlarında Hepatit B Serolojik Testlerinin Uygunsuz Kullanımı
}

\section{Inappropriate Use Of Serologic Tests For Hepatitis B In Health Care Personnels In Balikesir University Faculty Of Medicine Research And Practice Hospital}

\author{
Hacer ŞEN ${ }^{1}(\mathbb{D})$, Ayşe UYSAL ${ }^{2}(\mathbb{D})$, Mehmet Nur KAYA ${ }^{2}$ (D) Ali KIRIK $^{1}$ \\ ${ }^{1}$ Balıkesir Üniversitesi Tıp Fakültesi, İç Hastalıkları Anabilim Dalı, Balıkesir,TÜRKiYE \\ 2 Fatih Sultan Mehmet Eğitim ve Araştırma Hastanesi, İç Hastalıkları Kliniği, İstanbul,TÜRKiYE
}

öz.

Amaç: Hepatit B virüsü (HBV) akut ve kronik hepatite yol açıp, karaciğer sirozu ve hepatoselüler karsinoma neden olabilmektedir. Kan ve vücut sıvılarıyla temas sonucu bulaşan HBV, sağılık çalışanlarında enfeksiyon riski oluşturmaktadır. Bu nedenle sağlık çalışanlarına HBV taraması yapılmakta ve bağışıklı̆ı olmayanlara aşı ile proflaksi uygulanmaktadır. Yapılan taramada istenilen serolojik testlerinin doğru kullanılması ve yorumlanması oldukça önemlidir. HBV serolojik testlerin gereksiz istenmesi yüksek maliyet, iş gücü ve zaman kaybına yol açmaktadır. Bu retrospektif çalışmada, hastane çalışanlarında HBV enfeksiyonu serolojisinde uygunsuz test istemlerinin sayısı ve oluşturduğu mali yükün belirlenmesi amaçlanmıştır.

Materyal ve metod: Çalışma kapsamında hastanemiz bünyesinde görev alan sağlık çalışanlarının (doktor, hemşire, sağık memuru, teknisyen ve diğer hizmet görevlileri) 1 Ocak 2010 ile 31 Aralık 2019 tarihleri arasındaki kurum içi sağılık taraması kayıtları incelendi. Tüm çalışanların HBsAg ve Anti-HBs testleri incelendi. Tüm grubun ilk taramasında HBV bağışıklı̆ının varlığı nedeniyle sonraki taramalarda yapılan $\mathrm{HBsAg}$ ve Anti-HBs testleri uygunsuz istem olarak değerlendirildi.

Bulgular: Çalışmamızda sağlık personellerine yapılan $7486 \mathrm{HBV}$ serolojik testi incelendiğinde 4392 adet HbsAg ve 3094 adet Anti-Hbs testinin çalışıldığı görülmüştür. Testlerin değerlendirilmesinde 651 (\%9) HbsAg testinin ve 543 (\%7) Anti-Hbs testinin uygunsuz test olarak istendiği ve çalışıldığı saptanmıştır.

Sonuç: Sonuç olarak sağlık çalışanlarına yapılacak tarama testlerinde, kişinin aşılama açısından anamnezinin alınması, eski yapılan testlerin istem öncesi değerlendirilmesi uygunsuz istem oranlarını azaltacağını düşünüyoruz. Her hastanede bu taramaların tek bir bölümde, doktor tarafından yapılması ve hastanelerin hastane bilgi yönetim sisteminin algoritmayı uygulatması yönündeki ikaz sisteminin devreye sokması gereksiz istemler nedeniyle olacak mali kayıpları engelleyeceğini düşünüyoruz.

Anahtar Kelimeler: Hepatit B virüs enfeksiyonu, Sağıık çalışanı, Uygunsuz test istemi

Abstract

Background: Hepatitis B virus (HBV) can cause acute and chronic hepatitis, liver cirrhosis and hepatocellular carcinoma. Transmitted by contact with blood and body fluids, HBV poses an infection risk for healthcare workers. For this reason, healthcare workers are screened for HBV and those who are not immune are administered with vaccines for prophylaxis. It is quite important to use and interpretation correctly of the serologic tests requested in screening. Unnecessary request for HBV serologic tests leads to high cost, labor and time loss. In this retrospective study, it was aimed to determine number of inappropriate test requests and the financial burden of HBV infection serology in healthcare workers.

Materials and Methods: Within the scope of the study, in-house health screening records of healthcare workers (doctors, nurses, health officers, technicians and other service personnel) between January 1, 2010 and December 31, 2019 were examined. HBsAg and Anti-HBs tests of all employees were analyzed. HBsAg and Anti-HBs tests performed again in subsequent screenings were considered inappropriate request due to the presence of HBV immunity in first screening of the whole group.

Results: In our study, when the 7486 serologic tests for HBV applied to healthcare workers were examined, it was indicated that $4392 \mathrm{HbsAg}$ and $3094 \mathrm{Anti}-\mathrm{Hbs}$ tests were studied. In the evaluation of the tests, it was observed that 651 (\%9) HbsAg tests and 543 (\%7) Anti-Hbs tests were requested and studied as inappropriate tests. Conclusions: As a result, we consider that obtaining a medical history of the person and evaluating previous tests before the request in screening tests to be applied to healthcare workers in terms of vaccination will decrease the rate of inappropriate application. We think that these screenings in each hospital should be done in a single department by doctor and activation of a warning system for hospital information management system to apply the algorithm will prevent financial losses caused by superfluous requisitions.

Keywords: Hepatitis B virus infection, Healthcare workers, Inappropriate request of serologic tests

Sorumlu Yazar / Corresponding Author

\section{Dr.Hacer Şen}

Balıkesir Üniversitesi Tıp Fakültesi Araştırma ve Uygulama Hastanesi, Çă̆ı̧̧ Yerleşkesi, Bigadiç Yolu 17. Km, 10145, Balıkesir/TÜRKIYE

\section{E-mail: hcrgrsy@hotmail.com}

Geliş tarihi / Received: 01.12.2020

Kabul tarihi / Accepted: 24.11.2021

DOI: 10.35440/hutfd.834094 


\section{Giriş}

Hepatit B virüsü (HBV) akut ve kronik hepatite yol açıp karaciğer sirozu ve hepatosellüler karsinoma (HSK) neden olabilen bir DNA virüsüdür (1). Dünya genelinde yaklaşık 240 milyon hastada HBV taşıyıcılığı gözlenmekte olup bu durum küresel ölçekte bir halk sağlığı problemine neden olmaktadır (2,3). Kan ve vücut sıvılarıyla temas sonucu bulaşan HBV'nin dünya genelinde yaygın izlenmesi, hastane başvurularına bağlı olarak sağlık çalışanlarında artmış bulaş riskini doğurur. Bu nedenle tüm sağıık personellerine belirli aralıklarla HBV kontrolü yapılıp bağışıklık durumu olmayan gruba aşı ile profilaksisi uygulanmaktadır (4).

HBV'nin rutin serolojik değerlendirmesinde birçok antikor ve antijen düzeyinin tayini yapılmaktadır. Bunların içerisinde başlıca kullanılan testler $\mathrm{HBsAg}$, Anti-HBs, Anti-HBc IgM, Anti-HBc IgG, HBeAg ve Anti-HBe'dir (5). Bununla beraber asemptomatik hastalarda tarama amaçlı kullanılan testler HBsAg ve Anti-HBs olup, HBsAg negatifliğine eşlik eden Anti-HBs pozitifliği HBV'ye karşı bağışıklığın var olduğunun göstergesi kabul edilmektedir. Uluslararası kılavuzlarda üç doz aşı olmuş HBV bağışıklığı olan veya Anti-Hbs düzeyi $\geq 10 \mathrm{mIU} / \mathrm{mL}$ olan kişilerde herhangi bir bulaş durumunda risk olmaması nedeniyle ileriye yönelik takip veya tedavi önerilmemektedir (6). Bunun tek istisnası immunsupresif ilaç kullanımı olup bunun dışında kalan durumlarda HBV pozitifliği olan bireylerle temasta dahi ek bir tetkik ve tedavi önerisi bulunmamaktadır.

Sağlık çalışanlarına yönelik rutin uygulanan testler arasında yer alan HBV serolojik testleri doğru bir algoritmada istenmediği takdirde artmış bir maliyet ve iş gücü kaybına neden olmaktadır. Geçirilmiş HBV enfeksiyonunun öyküsü ya da serolojik testlerinin varlığı durumunda, tekrarlanan HBV serolojik testleri gereksizdir. Yine üç doz HBV aşısı olmuş ve tetkiklerinde Anti-Hbs cevabı görülenlerde tekrarlanan serolojik testler gereksiz tekrarlardır. Biz bu çalışmada HBV bağışıklığı olan sağlık çalışanlarında tekrarlanan HBV serolojik testlerinin neden olduğu maliyet kaybını incelemeyi amaçladık. Bildiğimiz kadarıyla bu çalışma ülkemizde sağlık çalışanlarında uygunsuz HBV kontrolünün incelendiği ilk araştırma olup çalışmamızın HBV taramaları nedeniyle ortaya çıkan maliyet ve iş gücü kaybını azaltmaya yönelik mevcut literatüre katkı sunacağı kanaatindeyiz.

\section{Materyal ve Metod}

Bu çalışma retrospektif, kesitsel nitelikte bir maliyet etkinlik çalışması olarak tasarlandı. Çalışma öncesinde Balıkesir Üniversitesi Tıp Fakültesi Klinik Araştırmalar Etik Kurulu'ndan 19.08.2020 tarih, 2020/123 sayı ile etik kurul onayı alınmış olup çalışma Helsinki Deklarasyonu'na uygun şekilde yapıldı.

Çalışma kapsamında üçüncü basmakta hizmet veren hastanemiz bünyesinde görev alan sağlık çalışanlarının (doktor, hemşire, sağlık memuru, teknisyen ve diğer hizmet görevlileri) 1 Ocak 2010 ile 31 Aralık 2019 tarihleri arasın daki kurum içi sağlık taraması kayıtları incelendi. Çalışmaya dahil edilen hastane personelinin merkez laboratuvarının seroloji biriminde tetkik edilen 7486 HBV serolojik testi tarandı. Tüm çalışanların $\mathrm{HBsAg}$ ve Anti-HBs testleri incelendi. Tüm grubun ilk taramasında HBV bağışıklığının varlığı nedeniyle sonraki taramalarda yapılan $\mathrm{HBsAg}$ ve AntiHBs testleri uygunsuz istem olarak değerlendirildi.

\section{Bulgular}

Hastanemiz il merkezinde üçüncü basamak hizmet veren tek hastanedir. HBV serolojik testleri hastanemizin merkez laboratuvarında seroloji biriminde çalışılmaktadır. Testler Architect i2000 (Abbott Laboratories, ABD) ve Architect i1000 (Abbott Laboratories, ABD) cihazlarında çalışılmıştır. Çalışmamızda sağlık personellerine yapılan 7486 Hepatit B serolojik testi incelendiğinde 4392 adet $\mathrm{HbsAg}$ ve 3094 adet Anti-Hbs testinin çalışıldığı görülmüştür. Testlerin değerlendirilmesinde 651 (\%9) HbsAg testinin ve 543 (\%7) Anti-Hbs testinin uygunsuz test olarak istendiği ve çalışıdığı saptanmıştır (Tablo 1).

Tablo 1. Çalışma kapsamında değerlendirilen HBV serolojisinin analizi

\begin{tabular}{cccccc}
\hline & $\begin{array}{c}\text { Uygunsuz } \\
\text { HbsAg }\end{array}$ & $\begin{array}{c}\text { Gerekli } \\
\text { HbsAg }\end{array}$ & $\begin{array}{c}\text { Uygunsuz } \\
\text { Anti-Hbs }\end{array}$ & $\begin{array}{c}\text { Gerekli } \\
\text { Anti-Hbs }\end{array}$ & Toplam \\
\hline $\begin{array}{c}\text { Çalışılan } \\
\text { test sayısı }\end{array}$ & 651 & 3741 & 543 & 2551 & 7486 \\
\hline $\begin{array}{c}\text { Çalışılan } \\
\text { test sayısı } \\
\text { (\%) }\end{array}$ & 9 & 50 & 7 & 34 & 100 \\
\hline
\end{tabular}

Uygunsuz test istemlerinin yapıldığı klinik bölümleri incelenmiştir. Uygunsuz istem açısından en yüksek oran \%34,6 ile nöroloji kliniği, ikinci en yüksek oran ise göğüs hastalıkları olarak saptanmıştır. Uygunsuz istem açısından en düşük oran ise \%8,65 ile enfeksiyon hastalıkları, ikinci en düşük oran ise \%12.2 ile üroloji kliniği olarak saptanmıştır (Tablo 2).

\section{Tartışma}

Sağlık alanında çalışanlar, hastalarla temas, kan ve vücut sıvılarının bulaşının olabilmesi nedeniyle birçok enfeksiyon hastalığı için risk altındadır. Bu risklerin başında HBV enfeksiyonu gelmektedir. Ülkemizden yapılan çeşitli çalışmalarda sağlık çalışanlarında HBV seropozitifliği \%0,7 ile \%3 arasında değişmektedir $(7,8)$. Hastalık bulaşı aşılama, koruyucu ekipman kullanımı ve standart önlemlerin alınması ve maruziyet riskinin azaltılması ile engellenebilmektedir. Sağıı çalışanları için taramanın yapılması ve HBV karşı aşılama önerilmektedir (6).

Sağlık çalışanlarının işe başlangıcında serolojik testleri ile değerlendirilmekte ve gerekiyorsa aşılama yapılmaktadır. HBV saptanan personel enfeksiyon hastalıkları biriminde takip edilmekte ve tedaviye alınmaktadır. Anti Hbs pozitifliğinde aşılamanın yapıldığı ya da doğal bağışıklanmanın gerçekleştiği bilinmektedir. Böyle kişilerde ek takibe gerek 
olmadığı ve HBV enfeksiyonu olan hastanın kan veya serumuyla temasta olduğunda Anti-Hbs düzeyine göre proflaksi uygulanmaktadır (6). Çalışmamız sağlık çalışanlarına yapılması gereken tarama testlerinin değerlendirilmesi şeklinde planlanmıştır.

Tablo 2. İstem yapılan birimlere göre test analiz oranları

\begin{tabular}{|c|c|c|c|c|}
\hline Birimler & $\begin{array}{l}\text { Uygunsuz } \\
\text { test sayısı }\end{array}$ & $\begin{array}{c}\text { Gerekli } \\
\text { test sayısı }\end{array}$ & $\begin{array}{c}\text { Toplam } \\
\text { test } \\
\text { sayısı }\end{array}$ & $\begin{array}{c}\text { Uygunsuz } \\
\text { test oranı } \\
(\%)\end{array}$ \\
\hline FTR Hastalıkları & 77 & 208 & 285 & 27.01 \\
\hline KDH Hastalıkları & 82 & 509 & 591 & 13.87 \\
\hline \multicolumn{5}{|l|}{ Enfeksiyon } \\
\hline Hastalıkları & 104 & 1098 & 1202 & 08.65 \\
\hline Ortopedi & 19 & 106 & 125 & 15.20 \\
\hline Üroloji & 12 & 87 & 99 & 12.12 \\
\hline Dahiliye & 455 & 2794 & 3249 & 14.00 \\
\hline Kardiyoloji & 56 & 298 & 354 & 15.81 \\
\hline Dermatoloji & 17 & 72 & 84 & 20.23 \\
\hline Nöroloji & 31 & 60 & 91 & 34.06 \\
\hline Genel Cerrahi & 81 & 234 & 315 & 25.71 \\
\hline KDC Hastalıkları & 26 & 176 & 202 & 12.87 \\
\hline Psikiyatri & 35 & 90 & 125 & 28.00 \\
\hline Göz Hastalıkları & 26 & 116 & 142 & 18.30 \\
\hline Plastik Cerrahi & 32 & 122 & 154 & 20.77 \\
\hline Beyin Cerrahi & 46 & 108 & 154 & 29.87 \\
\hline \multicolumn{5}{|l|}{ Göğüs } \\
\hline Hastalıkları & 66 & 130 & 196 & 33.67 \\
\hline KBB Hastalıkları & 29 & 84 & 113 & 25.66 \\
\hline
\end{tabular}

Başlıca HBV enfeksiyon tarama testleri HbsAg ve Anti Hbs olup, HBsAg pozitifliği akut ya da kronik enfeksiyonda gözlenirken, Anti-HBs pozitifliği kişinin aşılı ya da doğal yolla enfeksiyonu geçirerek bağışıklık kazandığını gösterir. Ciddi klinik tablolara yol açması ve kronikleşmesi nedeniyle bu enfeksiyonun tanısında laboratuvar testlerinin doğru kullanılması ve yorumlanması oldukça önemlidir. Bu amaçla tanısal algoritmalardan yararlanılır (9). Sağlık çalışanlarına yapılan ilk taramada Anti-Hbs pozitifliği saptandığında sonraki taramalarda $\mathrm{HBsAg}$ ve Anti-HBs testlerinin tekrarı uygunsuz istem olarak değerlendirilmektedir. Çalışmamızda (\%9) HbsAg testinin ve (\%7) Anti-Hbs testinin uygunsuz test olarak istendiği saptanmıştır. Ülkemizde yapılan bir çalışmada 3 yıllık yapılan tüm HBV serolojik testleri incelendiğinde uygunsuz $\mathrm{HbsAg}$ istemi \%1,34 uygunsuz Anti Hbs istemi ise \%2,23 olarak saptanmıştır (10). Bizim çalışmamızda uygunsuz test istemi daha fazla bulunmuştur. Çalışmanın 10 yıllık dönemi kapsaması ve çalışma grubunun serolojik taramanın yapılması gereken sağlık çalışanlarından oluşması nedeniyle uygunsuz test istem oranının artmasından sorumlu olduğunu düşünmekteyiz.

Sağlık çalışanlarına yapılan tarama testleri çeşitli klinikler tarafından istenmektedir. Çalışmamızda istemlerin yapıldığı klinikler tablo 2' de verilmiştir. Buna göre uygunsuz istemin en fazla yapıldığı klinikler nöroloji, göğüs hastalıkları ve fizik tedavi ve rehabilitasyon olarak belirlenmiştir. En az uygunsuz istem yapılan bölümler ise enfeksiyon hastalıklar, üroloji ve kalp damar cerrahisidir. Dumlupınar üniversitesinde yürütülen çalışmada da en fazla uygunsuz istem yapılan klinik nöroloji saptanmış, diğer bölümlerin uygunsuz istem oranları farklı bulunmuştur. Uygunsuz istem yapılmasının nedenleri tanısal algoritmaların kullanılmaması, hastane bilgi yönetim sisteminden hastanın önceki sonuçlarına bakılmaması, istemlerin yardımcı personel tarafından yapılması, iş yükünün fazla olması ve zaman kısıtlılığı olduğunu düşünmekteyiz. Bu taramaların tek birimden, algoritmaya uygun ve önceki test sonuçları görülerek yapılması uygunsuz istem oranlarını azaltacağı kanaatindeyiz. Serolojik testler için kullanılan kitlerin maliyeti laboratuarlar arasında farklı olmasına rağmen gereksiz istemlerin oluşturduğu mali yük sağlık harcamalarında ek yük getirmektedir. Hem maliyet artışı hem de çalışma gücünün gereksiz kullanımı kayıp olarak görülmelidir. Çalışmamızda yapılan gereksiz istemlerin maliyeti hesaplanmamış ancak oransal olarak bakıldığında önemli olduğunu görmekteyiz. Yapılan bazı çalışmalarda gereksiz serolojik istemlerin maliyeti hesaplanmış ve bu konuya dikkat çekilmiştir $(10,11)$. Sonuç olarak sağlık çalışanlarına yapılacak tarama testlerinde, kişinin aşılama açısından anamnezinin alınması, eski yapılan testlerin istem öncesi değerlendirilmesi uygunsuz istem oranlarını azaltacağını düşünüyoruz. Her hastanede bu taramaların tek bir bölümde, doktor tarafından yapılması ve hastanelerin hastane bilgi yönetim sisteminin algoritmayı uygulatması yönündeki ikaz sisteminin devreye sokması gereksiz istemler nedeniyle olacak mali kayıpları engelleyeceğini düşünüyoruz. Bu önlemler ayrıca hasta olan personelin doğru tanısında ve takibinde kolaylık sağlayacaktır.

Etik onam: Bu çalışma Balıkesir Üniversitesi, Tıp Fakültesi, Uygulama ve Araştırma Hastanesinde Yürütüldü. Çalışma Protokolü "Balıkesir Üniversitesi Tıp Fakültesi Klinik Araştırmalar Etik Kurulu" tarafinca onaylandı (19.08.2020 /2020:123).

\section{Yazar Katkıları:}

Konsept: A.K., M.N.K.

Literatür Tarama: H.Ş., A.U., A.K., M.N.K.

Tasarım: A.K., M.N.K.

Veri toplama: A.K.

Analiz ve yorum: A.U.

Makale yazımı: H.Ş., M.N.K., A.K.

Eleştirel incelenmesi: A.U.

Çıkar Çatışması: Herhangi bir çıkar çatışmamız bulunmamaktadir.

Finansal Destek: Araştırma kapsamında herhangi bir kurum ya da kuruluştan finansal destek sağlanmamıştır.

\section{Kaynaklar}

1. Trépo C, Chan HL, Lok A. Hepatitis B virus infection. Lancet. 2014;384: 2053-63.

2. Schweitzer A, Horn J, Mikolajczyk RT, Krause G, Ott JJ. Estimations of worldwide prevalence of chronic hepatitis $B$ virus infection: A systematic review of data published between 1965 and 2013. Lancet. 2015;386: 1546-55.

3. Ott JJ, Stevens GA, Groeger J, Wiersma ST. Global epidemiology of hepatitis B virüs infection: New estimates of age-specific HBsAg seroprevalence and endemicity. Vaccine. 2012;30(12): 2212-9. 
4. Terrault NA, Lok ASF, McMahon BJ, Chang KM, Hwang JP, Jonas $\mathrm{MM}$ et al. Update on prevention, diagnosis, and treatment of chronic hepatitis B: AASLD 2018 hepatitis B guidance. Hepatology. 2018;67(4):1560-99.

5. Krajden $M, M c N a b b$ G, Petric $M$. The laboratory diagnosis of hepatitis B virüs. Can J Infect Dis Med Microbiol. 2005;16: 65-72.

6. Schillie S, Murphy TV, Sawyer M, Ly K, Hughes E, Jiles R et al. CDC Guidance for Evaluating Health-Care Personnel for Hepatitis B Virus Protection and for Administering Postexposure Management. Recommendations and Reports. 2013;62(RR10):1-19

7. Karaosmanoglu HK, Aydin OA, Rahsan Ince E, Emirhan Isık $M$ and Kok M. HBV Serological Profiles and Vaccination Status among Healthcare Workers in Istanbul, Turkey. J Anc Dis Prev Rem. 2015;3(1):1-4.

8. Ozsoy MF, Oncul O, Cavuslu S, Erdemoglu A, Emekdas G and Pahsa A. Seroprevalences of hepatitis B and C among health care workers in Turkey. Journal of Viral Hepatitis. 2003;10: 150-156.

9. Weinbaum $\mathrm{CM}$, Williams I, Mast EE, Wang SA, Finelli $\mathrm{L}$, Wasley A, et al; Centers for Disease Control and Prevention. Recommendations for identifi cation and public health management of persons with chronic hepatitis $B$ virus infection. MMWR Recomm Rep. 2008; 57(RR-8): 1-20

10. Genç Ö, Aksu E. Dumlupınar Üniversitesi Evliya Çelebi Eğitim ve Araştırma Hastanesinde Hepatit B Serolojik Testlerinin Uygunsuz Kullanımı, Kütahya. Mikrobiyol Bul. 2014; 48(4): 618-627.

11. Özbek ÖA, Öktem MA, Akyüz A. Viral hepatit serolojisinde gereksiz test tekrarı. Mikrobiyol Bul. 2007; 41(2): 279-83. 